\title{
A Avaliação da Aprendizagem: um desafio a Gestão Escolar
}

\author{
Eloana Gomes Silva ${ }^{1}$; Francisco das Chagas Rodrigues Oliveira ${ }^{2}$
}

\begin{abstract}
Resumo: O artigo propôs uma discussão sobre a importância da avaliação da aprendizagem no processo educacional. Buscou-se encontrar respostas para conflitos entre o ato de avaliar e sua importância na aprendizagem dos alunos. Para isso, esta pesquisa baseou-se em vários autores que apreciam em suas obras uma reflexão acerca dos instrumentos avaliativos usados no contexto escolar, bem como o papel e uso da avaliação no processo ensino-aprendizagem. Observou-se diante das pesquisas que a avaliação não pode ser usada como forma de punir e exercer poder, tornando-se necessária a intensificação das relações entre professor x aluno, principalmente em termos metodológicos. Utilizou-se como método de análise prática a realização de entrevistas e aplicação de questionários para professores a alunos de uma Escola da rede Estadual de Ensino do município de Araripina - PE. Compreende-se então que aprimoramento metodológico, avaliação e aprendizagem, por conseguinte, são aspectos indissociáveis, intimamente ligados e influenciados pela socialização.
\end{abstract}

Palavras-Chave: Avaliação da Aprendizagem; Ensino Fundamental; Professor; Aprimoramento Metodológico.

\section{Evaluation of learning: a challenge to School Management}

\begin{abstract}
The article proposed a discussion on the importance of learning evaluation in the educational process. Sought to find answers to conflicts between the Act and its importance in evaluating students ' learning. For that, this research was based on several authors who enjoy in his works a reflection on the evaluative instruments used in the school context, as well as the role and use of evaluation in the teaching-learning process. It was noted before the polls that the evaluation cannot be used as a form of punishment and exerting power, making necessary the intensification of relations between professor $\mathrm{x}$ student, especially in methodological terms. It was used as a method of practical analysis interviews and questionnaires for teachers the students of a school in the State schools of the municipality of Araripina-PE. It is understandable then that methodological improvement, evaluation and learning, therefore, are inseparable aspects, intimately connected and influenced by socialization.
\end{abstract}

Keywords: evaluation of learning; Elementary School; Professor; Methodological Improvement.

\section{Introdução}

O tema avaliação é sempre um desafio na elaboração de um currículo. Embora fonte de muitos estudos e pesquisas, tem ainda diferentes modalidades, entre os quais citamos: Avaliação do processo, formativa, diagnóstica, prognóstica, etc.

\footnotetext{
1 Mestranda em Educação pela Anne Sullivan University, Especialista em Gestão na Educação com ênfase em Psicopedagogia pela Faculdade Leão Sampaio, graduada em Pedagogia pela Faculdade de Ciências, Tecnologia e Educação - FACITE, graduada em Letras pela Faculdade de Formação de Professores de Araripina - FAFOPA, E-mail: eloanagomes2014@ gmail.com;

${ }^{2}$ Professor Orientador Mestre em Gestão e Avaliação da Educação, facilitador do Seminário Temático de Avaliação do Sistema Educacional do Curso de Mestrado Internacional em Educação da Anne Sullivan University.
} 
O sistema educacional deve deixar claro, que a concepção de ensino aprendizagem, bem como as escolas pedagógicas, definição de objetivos e conteúdos de ensino estão intimamente ligadas à forma de avaliar, o que na maioria das vezes não acontece.

No ato de avaliar existem alguns processos que devem ser colocados em prática, são eles: processo de ensino, processo de aprendizagem e processo de desenvolvimento. Esses processos são indispensáveis, pois quando se ensina há aprendizagem através dela o desenvolvimento de suas habilidades, e isso fazem do aluno um ser mais seguro e capaz de superar o medo do processo avaliativo quando em sua forma teórica.

Com isso, este artigo, caracterizou-se como pesquisa bibliográfica e teve como objetivo geral detectar a evolutiva do processo avaliativo, seus aspectos, áreas de atuação e contribuição na prática pedagógica voltada para uma avaliação mediadora, bem como a sua contribuição no desenvolvimento integral do indivíduo.

A partir de estudos bibliográficos e investigativos pretende-se a proposição de um novo aprendizado sobre a avaliação da aprendizagem voltada, para o crescimento integral do ser humano, bem como, obter mais subsídios para discutir o trabalho docente.

Com isso, esta pesquisa está organizada em uma breve introdução, fundamentação teórica, conclusão e referências bibliográficas com relação de autores pesquisados que traçam idéias inovadores e sugestões para o processo avaliativo.

\title{
Contexto Histórico da Avaliação
}

Segundo Azevedo (1980), a avaliação é um "casaco de várias cores". Quando falamos em avaliação, com certeza não estamos fazendo referência sempre à mesma coisa; isso porque não há um só tipo de avaliação sobre o qual exista consenso.

Para Saul (1988, p. 61):

\begin{abstract}
A avaliação é uma constante em nosso dia-a-dia, através dela pode-se avaliar impressões e sentimentos, e isso ocorre cotidianamente, nas interações cotidianas, em casa, em nossa trajetória profissional, durante o lazer, a avaliação sempre se faz presente e inclui um julgamento de valor sobre nós mesmos, sobre o que estamos fazendo, sobre o resultado de trabalhos. Na ação escolar, a avaliação incide sobre o aproveitamento do aluno ou nosso plano de ação, que não pode ser confundida,
\end{abstract}



que a avaliação recai sobre inúmeros objetos, não só sobre o rendimento escolar.

Traçando seu contexto histórico, foi em meados de 1950, que a avaliação da aprendizagem passou a ser o foco mais frequentemente estudado na área. De 1950 para cá, vamos encontrar outros focos de avaliação - de projetos alternativos, por exemplo. Assim, em 1957, começaram a produzir rapidamente programas alternativos de Ciências e Física e, conseqüentemente, surgiu a preocupação com o efeito desses programas nas escolas. Isto ocorreu também no Brasil, só que com uma distância de quase duas décadas (SAUL, 1988, p. $61)$.

Nessa época, Barriga (1990) acrescenta que principalmente em São Paulo, as secretarias de Educação começaram a produzir propostas alternativas nas áreas do conhecimento e a se preocupar com a avaliação dessas ações curriculares. O Ministério da Educação e Cultura - MEC também passou a incentivar alguns projetos alternativos aos livros didáticos, o que, em geral, se fez acompanhar de um trabalho de treinamento de professores para desenvolverem tais projetos.

Vale ressaltar que o Brasil, nos anos 60 e 70, teve uma grande incidência de recomendações explícitas nos acordos internacionais, que previram, inclusive, a presença de técnicos norte-americanos para treinamento de professores brasileiros. De outro lado, teve-se, nessa época, um grande trânsito de professores brasileiros que faziam seus mestrados e doutorados nos Estados Unidos, trazendo toda uma bibliografia norte-americana que influenciou os cursos de nossas universidades (BARRIGA, 1990).

Em suas pesquisas sobre avaliação Saul (1988) afirma que vinham sempre com a seguinte encomenda: modificar o sistema de avaliação da aprendizagem, colocado como uma das necessidades das escolas.

Isso acontecia porque os professores a consideravam um problema crítico; não estavam satisfeitos com a avaliação realizada e queriam mudá-la, pois consideram que mudando a avaliação melhora-se a qualidade de ensino.

A avaliação é o fio condutor da nossa educação; então, deve-se avaliar o aluno levando em consideração todos os fatores, seja no campo afetivo, cognitivo, social ou familiar, que podem direto ou indiretamente estar interferindo em seus processos de aprender. A avaliação deve ser feita para promover transformações, e para isso, o professor precisa 
Id on Line Revista Multidisciplinar e de Psicoloqia

Id on Line Multidisciplinary Journal and Psycology

avaliar sua metodologia e verificar se está promovendo a inclusão ou a exclusão do indivíduo socialmente.

\section{Processo Legal da Avaliação: PCN e LDBEN}

Embora exista uma gama variada de possibilidades e formas de avaliação possíveis, os professores e escolas ainda parecem estar acorrentados ao modelo tradicional. Nessa linha de pensamento, nos diz Fleuri (apud VASCONCELOS 1994, p.42):

Para que serve a nota? Óbvio, responderam muitos - A nota serve para indicar o quanto o aluno aprendeu! Desta forma, proverá aqueles que estiverem preparados para exercer sua profissão e reterá os que não estiverem aptos. (...) Esta obviedade, porém, contesta diariamente pela prática escolar que os alunos aprovados demonstram que não aprenderam o que sua nota faz pré-supor.

A avaliação contempla dimensões maiores e não se reduz somente a atribuir notas. Pressupõe-se que o professor tenha autonomia suficiente para estabelecer seus próprios critérios baseados nos objetivos traçados junto com seus alunos, ele deve ver que as avaliações não são provas para testar conhecimentos assimilados, mas que tenham um significado mais próximo do original: detectar eventuais problemas e procurar soluções, de forma coletiva, professores e alunos.

De acordo com a concepção proposta nos Parâmetros Curriculares Nacionais.

A avaliação subsidia o professor com elementos para uma reflexão contínua sobre a sua prática, sobre a criação de novos instrumentos de trabalho e a retomada de aspectos que devem ser vistos, ajustados ou reconhecidos como adequados para o processo de aprendizagem individual ou de grupo. (BRASIL, 1997, p.81).

Segundo a Lei de Diretrizes e Bases da Educação Nacional (n. 9.394/96) o processo de avaliação deve ter como objetivo detectar problemas, servir como diagnóstico da realidade em função da qualidade que se deseja atingir, propondo assim sanar as deficiências durante o processo de ensino aprendizagem. $\mathrm{O}$ artigo $7^{\circ}$, em seu inciso II, é o primeiro que menciona a avaliação, e o faz vinculando-a à ideia de qualidade: "Art. $7^{\circ} O$ ensino é livre à iniciativa privada, atendidas as seguintes condições: II - autorização de funcionamento e avaliação de qualidade pelo poder público”; (LDBEN, 9394/96). 
Já seu Art. $9^{\circ}$ salienta que: A União incumbir-se-á de: VI. assegurar processo nacional de avaliação do rendimento escolar no ensino fundamental, médio e superior, em colaboração com os sistemas de ensino, objetivando a definição de prioridades e a melhoria da qualidade do ensino (LDBEN, 9394/96).

$\mathrm{O}$ artigo $24^{\circ}$ da referida lei acrescenta as seguintes informações:

Art. 24. A educação básica, nos níveis fundamental e médio, será organizada de acordo com as seguintes regras comuns:

II - a classificação em qualquer série ou etapa, exceto a primeira do ensino fundamental, pode ser feita: c) independentemente de escolarização anterior, mediante avaliação feita pela escola, que defina o grau de desenvolvimento e experiência do candidato e permita sua inscrição na série ou etapa adequada, conforme regulamentação do respectivo sistema de ensino;

III - nos estabelecimentos que adotam a progressão regular por série, o regimento escolar pode admitir formas de progressão parcial, desde que preservada a sequência do currículo, observadas as normas do respectivo sistema de ensino; $\mathrm{V}$ - a verificação do rendimento escolar observará os seguintes critérios:

a) avaliação contínua e cumulativa do desempenho do aluno, com prevalência dos aspectos qualitativos sobre os quantitativos e dos resultados ao longo do período sobre os de eventuais provas finais;

b) possibilidade de aceleração de estudos para alunos com atraso escolar;

c) possibilidade de avanço nos cursos e nas séries mediante verificação do aprendizado;

d) aproveitamento de estudos concluídos com êxito;

e) obrigatoriedade de estudos de recuperação, de preferência paralelos ao período letivo, para os casos de baixo rendimento escolar, a serem disciplinados pelas instituições de ensino em seus regimentos; (LDBEN, 9394/96).

A LDBEN, determina pela análise dos artigos acima que a avaliação seja contínua e cumulativa e que os aspectos qualitativos prevaleçam sobre os quantitativos. Da mesma forma, os resultados obtidos pelos estudantes ao longo do ano escolar devem ser mais valorizados que a nota da prova final.

Para que a avaliação sirva à aprendizagem é essencial conhecer cada aluno e suas necessidades. Assim o professor poderá pensar em caminhos - metodologias - para que todos alcancem os objetivos. 


\section{Metodologia}

Local do estudo - Para análise na realidade educacional foi realizada uma pesquisa de campo numa Escola da rede estadual de ensino do município de Araripina - PE, onde desenvolveu-se uma pesquisa exploratória com abordagem qualitativa com o objetivo de conhecer mais de perto a realidade e o cotidiano da prática pedagógica, particularmente no que se refere à avaliação da aprendizagem dos alunos.

Sujeitos - Os pesquisados foram 05 professores e 10 alunos do $8^{\circ}$ ano, (turmas "A", "B", "C" e "D") e $9^{\circ}$ ano (turmas "A" e "B") do Ensino Fundamental nos turnos matutino e vespertino.

Pesquisas bibliográficas - Foram levantados estudos bibliográficos sobre o tema, publicado em livros e publicações periódicas, como: jornais revistas, etc. Onde através destes obtivemos um aprofundamento do estudo, possibilitando ajustes ou fixação dos objetivos, formulação de hipóteses e redirecionamento da pesquisa de acordo com a relevância do tema. Caracterizando-se assim, como pesquisa bibliográfica com análise qualitativa, com o objetivo de servir como embasamento teórico e produção de conhecimento científico, tanto para os pesquisadores, como para a comunidade acadêmica e demais leitores.

A Pesquisa foi realizada por meio de questionários abertos, aos professores e semiaberto aos alunos da Escola pesquisada. No entanto, por necessidade em se fornecer mais informações ou detalhar melhor os dados prestados nos questionários, foram também realizadas algumas entrevistas, as quais enriqueceram e contribuíram para a consubstanciação da pesquisa.

Amostra Probabilística - Os dados coletados foram armazenados como banco de dados transformados em gráficos e tabelas, desenvolvido especificamente para essa finalidade, facilitando a sistematização, análise e interpretação de informações que resultam na elaboração desse trabalho. 


\section{Resultados e Discussão}

A escola que serviu-nos de campo de pesquisa foi uma unidade da rede estadual de ensino, onde atende de Ensino Fundamental II e Médio, nos horários, matutino, vespertino e noturno, sendo sua clientela oriunda da classe média baixa.

Dentre os professores pesquisados, $50 \%$ eram do sexo feminino e $50 \%$ eram do sexo masculino. Observou-se ainda que todos os entrevistados possuem entre 30 e 35 anos idade e trabalham na escola com tempo de serviço entre 04 a 14 anos, como mostra o Gráfico 01:

Gráfico 01: Tempo de Serviço do Corpo Docente

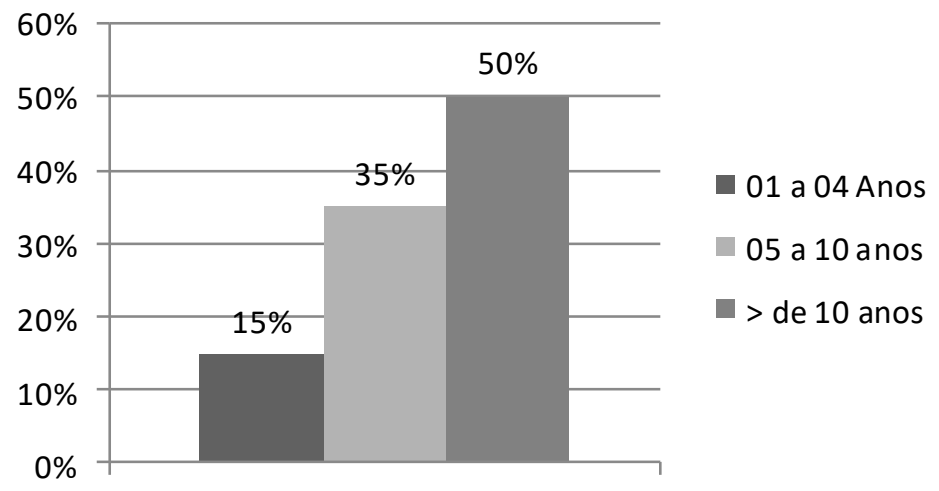

Fonte: Pesquisa Direta

No Gráfico 01 observa-se que 50\% dos professores estão na escola há mais de 10 anos, outros 35\% trabalham na escola no período entre 05 a 10 anos. Apenas $15 \%$ atuam na escola entre 01 a 04 anos.

Em relação ao exercício da profissão todos afirmaram ter escolhido o caminho da educação, ser professor, por ter vocação e gostar de repassar seus conhecimentos. Partindo para as questões específicas sobre a Avaliação, os docentes conceituaram-na da seguinte forma: 
Id on Line Revista Multidisciplinar e de Psicoloqia

Id on Line Multidisciplinary Journal and Psycology

Gráfico 02: Conceito de Avaliação segundo o Corpo Docente entrevistado

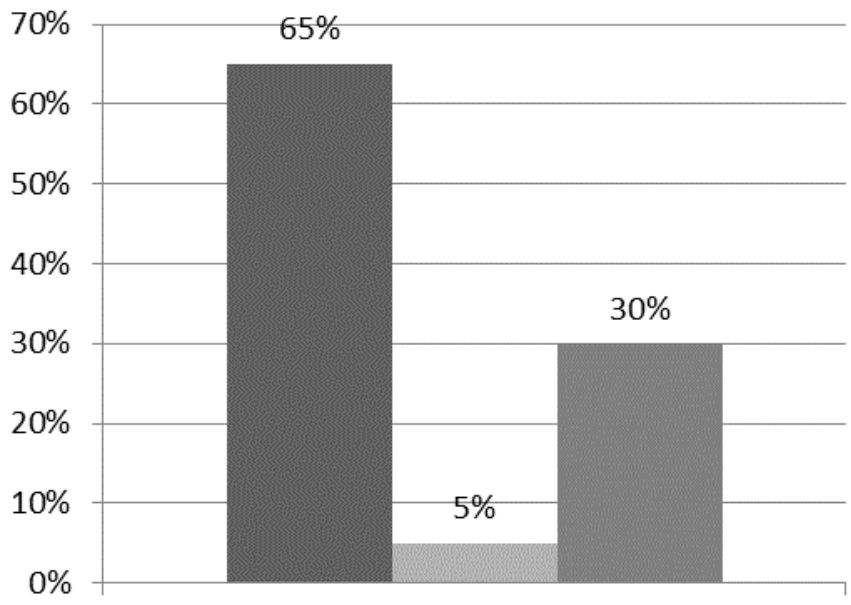

Fonte: Pesquisa Direta
Processo de Observação, segundo critérios préestabelecidos, de uma ou várias habilidades

- Olhar Geral sobre as pessoas que estão em estudo, analisando habilidades e competências

- Analisar o rendimento do aprendiz em relação ao conteúdo estudado

Diante do Gráfico 02 percebe-se que 65\% dos docentes informaram que a avaliação trata-se do de um processo de observação que segue critérios pré-estabelecidos; $30 \%$ afirmaram ser a maneira de se analisar o rendimento dos alunos e 5\% disseram que trata-se de um olhar geral sobre os alunos no desenvolvimento de sua habilidades e competências.

Os pesquisados ainda conceituaram a Avaliação da Aprendizagem como:

Gráfico 03: Avaliação da Aprendizagem segundo os professores entrevistados.

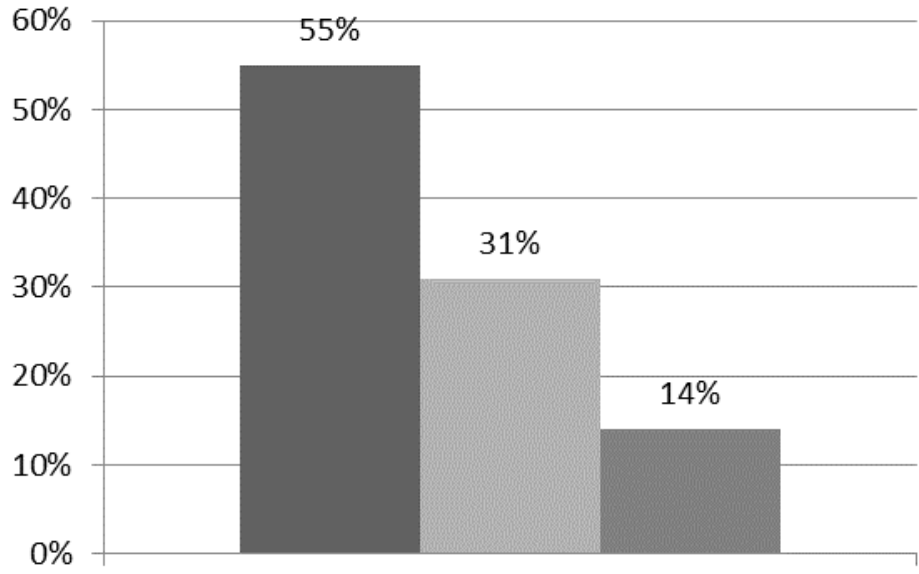

.Fonte: Pesquisa Direta
Todo processo verificação de aprendizagem nos seus aspectos específicos e gerais

Método de identificação do nível de aprendizagem do aluno, considerando suas singularidades

- Técnica que visa fornecer informações que permitam aos agentes escolares determinar o grau de conhecimento dos alunos

No Gráfico 03, observa-se que 55\% dos pesquisados caracteriza a Avaliação da aprendizagem como todo processo de verificação da aprendizagem, meio pelo qual os alunos devem passar para a mensuração dos seus conhecimentos adquiridos. Já 31\% consideram-na 
como método de identificação do nível de aprendizagem dos alunos, mas levando em conta suas singularidades (limitações, dificuldades). Outros 14\% consideram como uma técnica que fornece informações para que possam determinar como anda o grau de conhecimento de seus alunos.

Quanto à questão que trata de como o docente desenvolve o processo de ensino aprendizagem em sala de aula, observou-se que $70 \%$ dos professores desenvolvem o processo de ensino aprendizagem, ensinando o aluno a buscar o conhecimento, e não entregá-los prontos, incentivando-os a investigação, incitando sua curiosidade, para que o saber não seja estagnado. Outros 25\%, afirmam trabalhar o diálogo com os alunos, assim descobrem um pouco de cada um. E 5\% responderam que através do levantamento dos conhecimentos prévios dos alunos, leituras e comentários orais, como mostra o gráfico 04 abaixo:

Gráfico 04: Métodos que os professores pesquisados utilizam para desenvolver o processo de ensino aprendizagem.

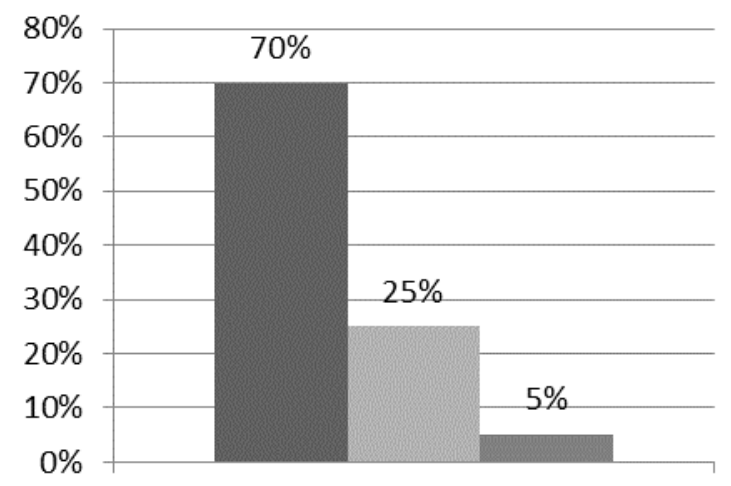

Fonte: Pesquisa Direta
Ensinando o aluno a buscar o conhecimento além dos muros da escola, incentivando a investigação, incitá-los a curiosidade, para que o saber jamais seja estagnado.

Dialogando com os aluno; Exposição dos conteúdos e discussão.

- Realizando levantamento dos conhecimentos prévios dos alunos; leituras e comentários orais

Quanto às estratégias que são utilizadas para a aprendizagem dos alunos $65 \%$ disseram que trabalham através da exposição dialogada, pesquisa e livro didático e 35\% através de leituras, comentários, análises lingüísticas e produções (escrita e reescrita), como mostra o Gráfico 05: 
Id on Line Revista Multidisciplinar e de Psicoloqia

Id on Line Multidisciplinary Journal and Psycology

Gráfico 05: estratégias que são utilizadas para a aprendizagem dos alunos pelos professores entrevistados.

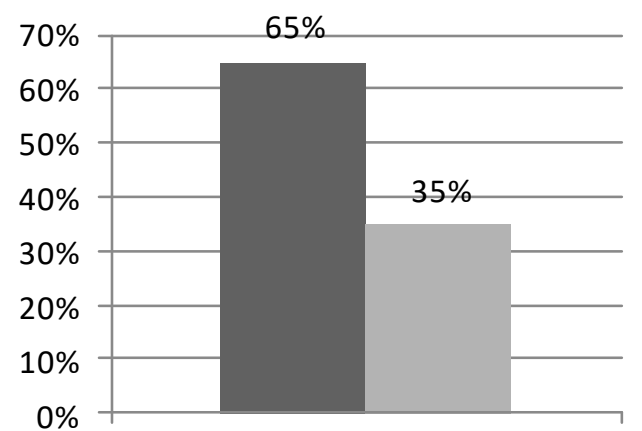

- Exposição dialogada, pesquisa e livro didático

- leituras, comentários, análises lingüísticas e produções (escrita e reescrita)

Fonte: Pesquisa Direta

Questionando os docentes quanto à forma que avalia seus alunos, $45 \%$ informou que avaliam de forma geral e específica, através da participação individual, cooperação nos trabalhos em grupo, avaliações bimestrais; 25\% afirmaram acompanhar a realização de atividades seguida de discussão e observação direta; outros $30 \%$ disseram que avaliam observando a expressão oral e aplicação de atividades escritas, como mostra o gráfico 06:

Gráfico 06: Formas de avaliação dos professores entrevistados.

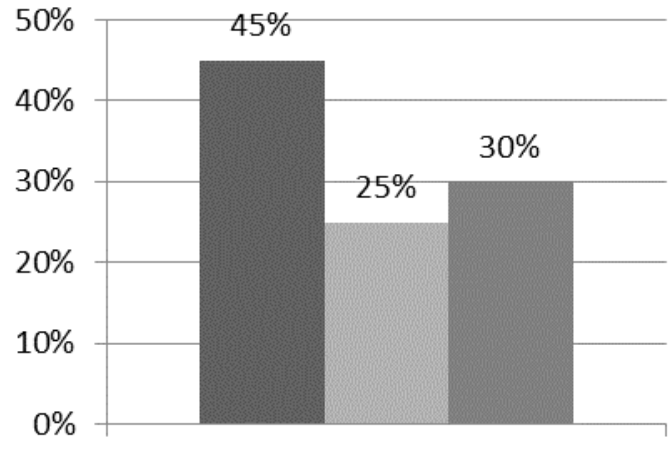

Fonte: Pesquisa Direta
- Avaliam de forma geral e específica, através da participação individual, cooperação nos trabalhos em grupo e avaliações bimestrais

Acompanham a realização de atividades seguida de discussão e observação direta

- Avaliam observando a expressão oral e aplicação de atividades escritas

Ainda em relação às formas de avaliação $100 \%$ dos professores pesquisados disseram que costumam oportunizar avaliações coletivas entre seus alunos, através de pesquisas e elaboração de trabalhos para apresentação em grupo, porém o desempenho é avaliado individualmente. 
Questionando-os como encaram o erro, os resultados ruins de seus alunos, 50\% dos docentes informaram que consideram o diálogo o melhor meio de solução em qualquer problema e $50 \%$ já acham que o erro é um ponto de partida para um trabalham mais específico e para a realização de uma auto-avaliação.

Quanto aos instrumentos que utilizam para promover a avaliação, resultou o seguinte:

Gráfico 07: Instrumentos utilizados para promover a avaliação

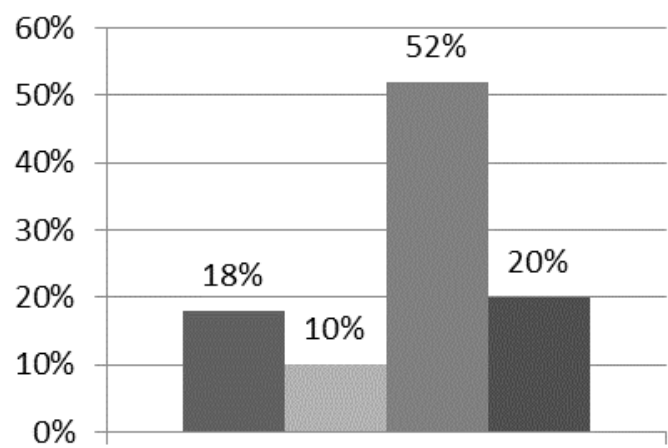

Fonte: Pesquisa Direta
- Atividades em grupo (jogos, dinâmicas, gincanas)

- Participação nas atividades e aplicação de testes escritos

- Observação da expressão oral, trabalhos em grupo, e participação em atividades orais e escritas

- Avaliação bimestral com questões objetivas e dicurssivas

Em relação às principais dificuldades que encontram para a realização da avaliação, os docentes relacionaram as seguintes:

Gráfico 08: Principais dificuldades que encontram para a realização da avaliação.

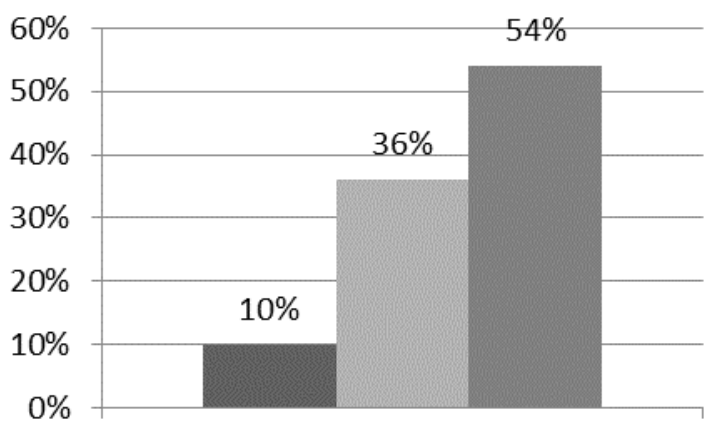

Desinteresse, baixa auto-estima dos alunos

Disponibilidade de tempo para leitura, estudo extra-classe

Ausência de acompanhamento dos pais e falta de estudo pelos alunos

Fonte: Pesquisa Direta

Observa-se pelo Gráfico 08 que 54\% dos docentes sentem dificuldade em avaliar seus alunos devido a ausência de acompanhamento dos pais e falta de estudo pelos alunos dos conteúdos trabalhados em casa. Outros 36\% atribuem esta dificuldade a falta de 
disponibilidade de tempo para leitura e estudo extra-classe para aprimorar seu trabalho. E $10 \%$ disseram que isso ocorre principalmente devido ao desinteresse e baixa auto-estima dos alunos.

Quanto aos questionários aplicados aos alunos, $67 \%$ eram alunos do $8^{\circ}$ ano $\left(7^{\mathrm{a}}\right.$ série) e $33 \%$ eram do $9^{\circ}$ ano ( $8^{\mathrm{a}}$ série $)$ do ensino fundamental.

Em relação a faixa etária dos pesquisados, obteve-se o seguinte: $36 \%$ dos alunos pesquisados tinham 13 anos, 19/5 tinham 12 anos, 17\% tinham 11 anos e 13\% tinham 17 anos. Analisando estes dados percebe-se que há uma certa distorção idade/série com alunos, principalmente do turno vespertino, pois estão com 17 anos ainda cursando o $9^{\circ}$ ano $\left(8^{\mathrm{a}}\right.$ série $)$ do ensino fundamental.

Quanto a pergunta que trata da importância da educação escolar na sua vida, 100\% dos alunos responderam que sim, a considera essencial em sua vida, pois a formação educacional na vida do ser humano é fundamental para os dias atuais.

Pergunta-se aos alunos pesquisados em relação a que aspectos estão relacionadas suas dificuldades, 50\% afirmaram ser a falta de estudo, pois fazem as atividades na maioria das vezes apenas para ganhar notas ou pontos; $30 \%$ responderam ser a falta de entendimento do conteúdo que está sendo lecionado na sala de aula; e 20\% disseram que sentem dificuldades em certas disciplinas por não gosta do conteúdo que está sendo explicado.

Gráfico 09: Em que está relacionado às dificuldades do aluno

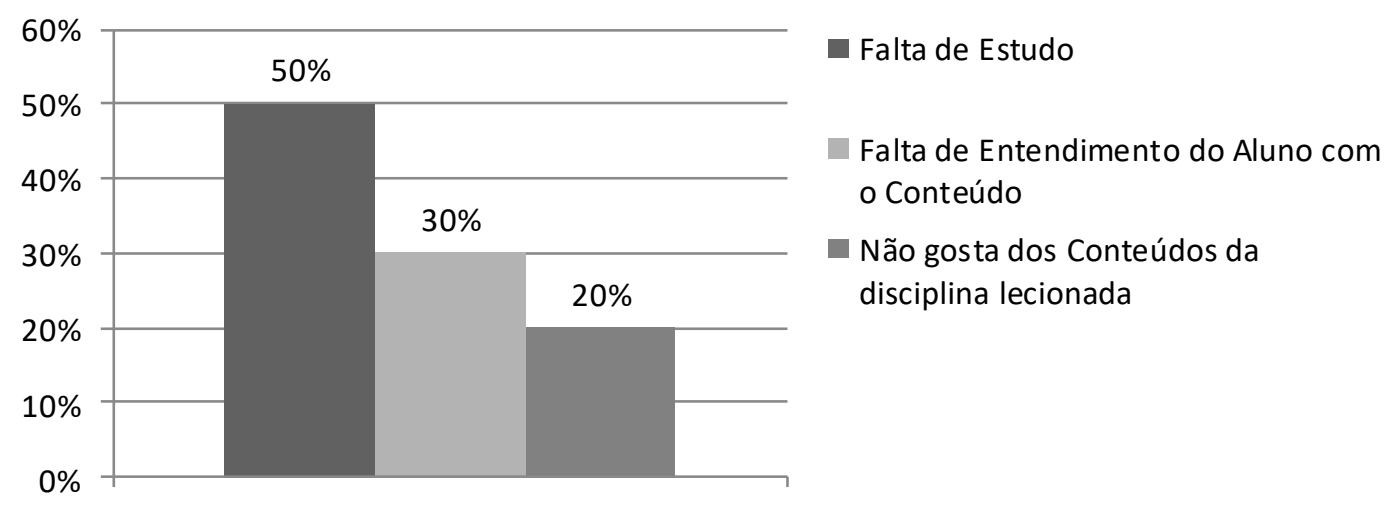

Fonte: Pesquisa Direta. 
Id on Line Revista Multidisciplinar e de Psicoloqia

Id on Line Multidisciplinary Journal and Psycology

Para responder a pergunta trata a respeito do envolvimento da família do aluno com as atividades docente da escola, $70 \%$ responderam que sim, pois, seus pais são sempre convidados a participar das atividades, e isso ajuda bastante no seu desempenho; e 30\% informaram que às vezes, pois seus pais só vão à escola quando há reuniões.

Gráfico 10: Envolvimento da família do aluno com as atividades docente da escola

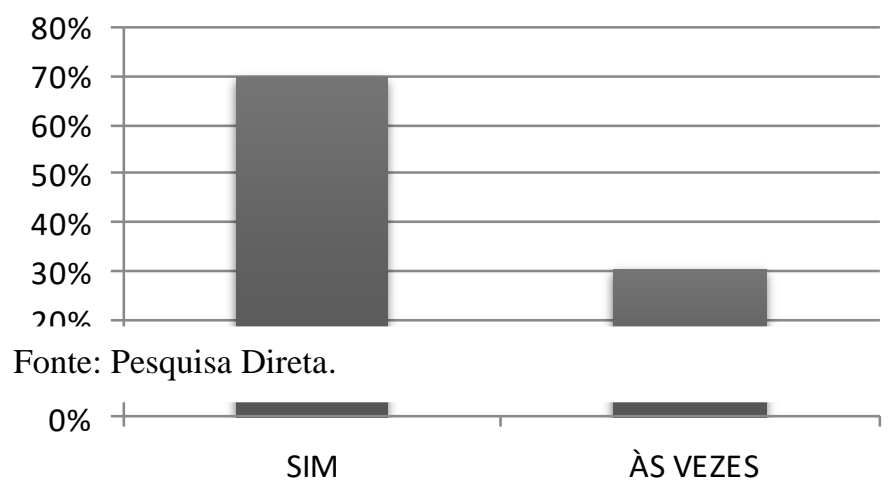

Já em relação às questões específicas sobre a forma de avaliar de seus professores, os alunos informaram o seguinte:

Tabela 01: Opinião dos alunos quanto a forma de avaliar de seus professores.

\begin{tabular}{|l|l|l|l|c|}
\hline \multicolumn{2}{|c|}{ O MEU PROFESSOR, USUALMENTE: } & \multicolumn{3}{c|}{ PERCENTUAL } \\
\cline { 2 - 5 } & Sim & Não & Às vezes & Raramente \\
\hline 1. Dá instruções claras & $80 \%$ & $17 \%$ & $3 \%$ & \\
\hline 2. Trata todos imparcialmente & & $40 \%$ & $40 \%$ & \\
\hline 3. Mostra-se disponível para ajudar fora da aula & $30 \%$ & $20 \%$ & $20 \%$ & $30 \%$ \\
\hline 4. Torna claros os objetivos da aula & $40 \%$ & $20 \%$ & $40 \%$ & \\
\hline 5. Avalia os meus trabalhos em tempo razoável & $35 \%$ & $25 \%$ & $30 \%$ & $10 \%$ \\
\hline 6. Relaciona os conteúdos da aula com matérias atuais & $80 \%$ & & $20 \%$ & \\
\hline 7. Respeita as diferentes opiniões & $70 \%$ & & $20 \%$ & $10 \%$ \\
\hline 8. Encoraja os alunos a aprender & $80 \%$ & $20 \%$ & & \\
\hline 9. Utiliza diversas atividades na aula & $60 \%$ & $20 \%$ & $20 \%$ & \\
\hline 10. Comunica de forma clara & $70 \%$ & $20 \%$ & $10 \%$ & \\
\hline 11. Gere a turma sem grandes interrupções & $20 \%$ & $40 \%$ & $20 \%$ & $20 \%$ \\
\hline 12. Mostra respeito por todos os alunos & $100 \%$ & & & \\
\hline 13. Mantém um clima de ordem e disciplina & $80 \%$ & $20 \%$ & & \\
\hline $\begin{array}{l}\text { 14. Temos oportunidades de auto-avaliação e de expressar ao } \\
\text { professor as dificuldades percebidas em sua disciplina para mútuo } \\
\text { crescimento. }\end{array}$ & $45 \%$ & & $35 \%$ & $20 \%$ \\
\hline 15. Sabe dos assuntos que ensina & & & \\
\hline
\end{tabular}


Id on Line Revista Multidisciplinar e de Psicoloqia

Id on Line Multidisciplinary Journal and Psycology

\begin{tabular}{|l|c|c|c|c|}
\hline 16. Define o plano de trabalho a médio e longo termo & $80 \%$ & & $20 \%$ & \\
\hline 17. Mantém expectativas elevadas & $100 \%$ & & & \\
\hline 18. Ajuda-me a manter altas expectativas & $100 \%$ & & & \\
\hline $\begin{array}{l}\text { 19. Os instrumentos de avaliação são variados, adaptados às } \\
\text { diferenças individuais e ajudam no nosso crescimento. }\end{array}$ & $80 \%$ & & $20 \%$ & \\
\hline 20. Comunica comigo de forma honesta & $80 \%$ & $20 \%$ & & \\
\hline
\end{tabular}

Fonte: Pesquisa Direta.

Observa-se pela Tabela 01 que com relação a todas as questões respondidas, a maioria optou pela melhor resposta, nesta escola deve-se apenas trabalhar mais a questão afetiva, pois, percebe-se, como por exemplo, no item 3, apenas $30 \%$ dos professores mostra-se disponível para ajudar fora da aula; e quanto a avaliação (Item 14), 55\% afirmaram que apenas às vezes ou raramente tem oportunidades de auto-avaliação e de expressar ao professor as dificuldades percebidas em sua disciplina para mútuo crescimento.

Sendo assim, o professor deve procurar por metodologias de ensino que envolva a todos, desencadeie o trabalho em equipe, a interação para obter-se um melhor relacionamento na turma.

\section{Conclusão}

A avaliação é o fio condutor da nossa educação; então, deve-se avaliar o aluno levando em consideração o seu ponto de vista; a forma como ele vê a sua dificuldade.

Criam-se mil fórmulas e diferentes maneiras de avaliar, mas se o aluno não for ouvido, de nada valerá a avaliação escolar, tanto de alunos com dificuldades quanto os outros.

Sendo assim, os conhecimentos desta pesquisa podem contribuir para uma avaliação mais abrangente junto aos alunos, considerando fatores afetivos, cognitivos, sociais, familiares, escolares que poderão estar interferindo em seus processos de aprender, como diagnosticou na pesquisa de campo deste artigo.

A avaliação deve ser feita para promover transformações, e para isso, o professor precisa avaliar sua metodologia e verificar se está promovendo a inclusão ou a exclusão do indivíduo socialmente. 
É necessário que o professor tome atitudes e proporcione aos seus alunos um envolvimento amplo neste processo, responsabilizando-o também neste avaliar contínuo, cabendo à Psicopedagogia auxiliar as instituições nesta busca por mudanças efetivas.

Concluindo, com as palavras de Luckesi (2000, p.45), “(...) Por si, a avaliação deve ser inclusiva. Por ela, por onde quer que passe, não há exclusão, mas sim diagnóstico e construção."

\section{Referências}

AZEVEDO, Maria Amélia. Avaliação educacional: medo e poder!!! In: Educação $\boldsymbol{e}$ Avaliação. São Paulo: Cortez, 1980.

BARRIGA, Ángel Diaz. Curriculum y evaluación escolar. Buenos Aires: Instituto de Estudos y Acción Social. Rey Argentina S.A. Arque Grupo Editor S.A., 1990.

BRASIL. Lei de diretrizes e bases da educação nacional. Lei $n^{\circ} 9394$, de dezembro de 1996.

BRASIL. Secretaria de Educação Fundamental. Parâmetros Curriculares Nacionais: História. Brasília: MEC/SEF, 1997.

LUCKESI, Cipriano C. Avaliação da Aprendizagem Escolar. 11 ed. São Paulo:Cortez, 2000.

SAUL, Ana Maria A. Avaliação emancipatória, desafio á teoria e a prática de avaliação e reformulação de currículo. São Paulo: Cortez/Autores Associados, 1988.

SOUZA, Clarilza Prado. Avaliação do Rendimento Escolar. São Paulo: Gente, 1991.

VASCOCELlOS, Celso dos Santos. Avaliação: Concepção Dialética-Libertadora do Processo de Avaliação Escolar. São Paulo: Libertad, 1994.

Como citar este artigo (Formato ABNT):

SILVA, E.G.; OLIVEIRA, F.C.R. Avaliação da Aprendizagem: um desafio a Gestão. Id on Line Revista Multidisciplinar e de Psicologia, Set-Out de 2016, vol.10, n.31, Supl 2, p. 66-80. ISSN 1981-1179. 